\title{
Considerations About the Role of the CCR5 Gene in Juvenile Idiopathic Arthritis - Look at the Whole or Put All Parts Together?
}

\author{
Tiago Degani Veit ${ }^{*}$, , Ilóite Scheibel ${ }^{2}$ and José Artur B. Chies ${ }^{1}$ \\ ${ }^{I}$ Programa de Pós-Graduação em Genética e Biologia Molecular, Universidade Federal do Rio Grande do Sul, Porto \\ Alegre, Brazil \\ ${ }^{2}$ Grupo Hospitalar Conceição, Porto Alegre, Brazil
}

\section{DEAR EDITOR,}

The CCR5 is an important chemockine receptor. The gene coding for this protein initially gain attention when a variant called CCR5 332 (due to the occurrence of a 32 base pair deletion in its coding region) was associated to resistance against HIV infection. Thus, homozigous CCR5 32 individuals were shown to be protected against HIV-1 infection and heterozigous individuals presented a delay on AIDS development [1,2]. From this sparkling start, the CCR5 gene, and specifically the CCR $5 \Delta 32$ allele, become a candidate and a target to several studies intending to understand and explore such "beneficial allelic variant". In this way, in 1998 the CCR5 32 variant was suggested to act as a protective factor against the development of rheumatoid arthritis (RA) [3] and since then several works were published attempting to corroborate or refute this initial idea and also attempting to inhibit this chemokine receptor, as a therapeutic approach in order to modulate rheumatoid arthitis symptons [4-9].

Considering the potential association of this chemockine receptor and rheumatoid arthritis, it is tempting to analyze the effect of this same genetic variant in other rheumatological conditions. Juvenile idiopathic arthritis (JIA), for instance, is the most common chronic rheumatic disease of childhood and is defined as a chronic inflammatory condition that affects the synovial joints of individuals aged up to 16 years and that persists for at least six weeks. JIA is of unknown etiology, although there is evidence that genetic and immunological factors are involved in its development. A recently metaanalysis, performed by Hinks et al. suggested an association of the CCR5 gene with juvenile idiopathic arthritis [10]. Although we also believe that CCR5 is an important molecule in JIA, our results point to opposite directions. While Hinks et al. affirm that the CCR5 32 gene variant is associated with protection from developing JIA, our results suggest that this variant is associated with the most severe forms of the disease [11].

*Address correspondence to this author at the Programa de Pós-Graduação em Genética e Biologia Molecular, Universidade Federal do Rio Grande do Sul, Porto Alegre, Brazil; Tel: 55513308 6740; Fax: 55513308 7311;

E-mail: tiagoveit@terra.com.br
As our study was not included in the meta-analysis performed by Hinks et al., we believe that some considerations should be done in order to not avoid important information concerning the involvement of the CCR5 molecule in JIA. The reason for the non inclusion of our work on the meta-analysis was "significant heterogeneity between the studies". Although we can agree that the CCR5 332 allelic frequency among our control sample was low $(3.8 \%)$ as compared to those on the other three studies included at the meta-analysis $(10.0 \%$ in a cohort from the United States [6], $11.5 \%$ in a population from Norway [9] and $11.4 \%$ for the United Kingdom study [10]), the frequency of the CCR5 $\Delta 32$ allele among JIA patients was quite similar amongst all studies, including ours $(9.4,8.8$, 9.7 , and 9.2 respectively). The Brazilian population is considered to be highly miscegenated, nevertheless, in our sample we only included individuals classified as Europeandescendent and from the same geographic region (Rio Grande do Sul, the southernmost Brazilian state). Rio Grande do Sul is a state where African-derived genetic contribution to individuals classified as Euro-descendent is restricted, as previously discussed [12]. Also, different works have already assessed the CCR5 $\Delta 32$ allelic frequency in the South population of Brazil, with frequency values ranging from 0.035 to 0.066 [12-16]. The ethnic classification used by our group (based on phenotypic characteristics of individuals and ethnicity data of parents/grandparents reported by the participants) is widely adopted in our country. Although we must admit that individuals classified as European-derived or African-derived can present a certain degree of admixture, a recent study which assessed individual interethnic admixture using a 48-insertiondeletion Ancestry-Informative Marker panel, identified a very high level of European contribution (94\%) and far fewer Native American (5\%) and African (1\%) genes in a sample of 81 European-derived individuals from southern Brazil [17]. Therefore, the ethnic classification of the individuals in our work as European-descendent is supported both by the CCR5 32 allelic frequencies among Southern Brazilian populations and by the low degree of admixture in this region.

The ethnic background of a given population certainly interferes in the expression of any given feature. For example, the analysis performed by Lindner et al. [9] in the 
Norwegian cohort do not supported an association between the CCR5Delta32 allele and Norwegian RA or JIA patients. Nevertheless, when their data was included in a metaanalysis, overall results still provide evidence for a role for CCR5Delta32 in RA. once again highlighting the importance of consider the genetic/ethnic background of the analyzed population.

Even considering that data should be analyzed in a way to minimize the effects of genetic/inter-ethnic diversity, other aspects are also relevant to establish the real role of the CCR5 molecule on JIA. For instance, in the Brazilian cohort it was possible to identify a CCR $5 \Delta 32$ allelic frequency gradient that correlated with JIA subtypes classified according to the number of affected joints, the presence of rheumatoid factor (RF), and the degree of systemic inflammation, suggesting a relationship between the absence of the CCR5 chemokine receptor and the JIA subtypes with a broader inflammatory involvement (namely polyarticular $\mathrm{RF}+$ and systemic subtypes). Curiously, the only CCR5 $\Delta 32$ homozygous patient in this sample had systemic JIA and presented severe clinical features. Other works also reported severe clinical conditions in CCR5 32 homozygous JIA patients. A CCR5 $\Delta 32$ homozygous JIA individual with a severe extended oligoarthritis subtype and a CCR5 $\Delta 32$ homozygous JIA patient with a destructive systemic disease with a polyarticular course were reported by two independent groups $[18,19]$. All these studies, added to the fact that six patients on the study from Hinks et al. were also CCR5 432 homozygous indicate that the absence of a functional CCR5 molecule does not prevent JIA development. Actually, the absence of a functional CCR5 molecule was already associated with deleterious symptoms, or negative outcomes, in several different inflammatory and infectious diseases and even with cancer development (see review [20]).

In JIA, the importance of the CCR5 molecule is highlighted not only by its pro-inflammatory role, but also by its involvement as a regulatory molecule [21, 22]. It is worth mentioning that the level of CCR5 expression (or the absence of such expression), as well as the co-expression of other chemokine receptors, can influence the migration pattern of proinflammatory $\mathrm{T}$ cells into the synovium and thus the susceptibility to JIA, as previously suggested [23, 24]. These two works have reported the involvement of the CCR5 molecule in the T cell memory compartment of JIA patients, at the level of both $\mathrm{T}$ cell memory recruitment and differentiation. They also suggested that CCR5 expression differently affects migration and accumulation of $\mathrm{T}$ cells at the inflammation site. Specifically, it was observed, when analyzing CD27+ memory $T$ cells in the synovium fluid of JIA patients, that such cell subpopulation expressed CCR7 more highly than CCR5 and that a differential pattern of CCR5 expression among CD27- and CD27+ memory cells was associated to different migratory properties of these memory cells into and within the synovial tissue [24].

The CCR5 knockout mouse model provides interesting data concerning the effects of the lack of CCR5 expression on $\mathrm{T}$ cell migration. Although these CCR5 knockout mice apparently have a normal immune system, when they are infected with a mouse-adapted strain of influenza-A virus they display increased mortality rates associated with acute, severe pneumonitis, due to altered patterns of immune cell migration in and out of the infected lungs [25]. Thus, the absence of a functional CCR5 molecule affects several different $\mathrm{T}$ cell subpopulations, including memory and regulatory cells, and can, direct or indirectly, not only impair the establishment of immune responses but also interfere on the balance of the immune system, allowing the establishment of exacerbated inflammatory responses.

Juvenile Idiopathic Arthritis is a complex disease, characterized by the existence of a number of subtypes correlated to different clinical features. Taking together, all data from the literature indicates that JIA individuals with different disease subtypes will be distinctly affected by the absence, or by a lower expression, of the CCR5 molecule. Therefore, it will be quite important not only to consider all the studies approaching human populations as a whole, but also to analyze specific subgroups of individuals, i.e. affected by certain JIA subtypes, with specific disease courses and so on. In conclusion, in JIA, the CCR5 432 allele seems to be much more a disease modifying factor than a susceptibility factor and should, therefore, be analyzed under this perspective. We believe that the absence or the reduced expression of a functional CCR5 molecule on JIA patients provokes a dysregulated pro-inflammatory response on such individuals. More studies on the genetics and expression of this molecule in different human populations should be performed in order to clearly identify the involvement of the CCR5 molecule in JIA and in other rheumatologic conditions as well as the potential consequences of antiCCR5 therapies.

\section{ACKNOWLEDGEMENT}

None declared.

\section{CONFLICT OF INTEREST}

We declare that we have no conflicts of interest in the authorship or publication of this contribution.

\section{ABBREVIATIONS}

CCR5 $=$ Chemockine receptor gene 5

JIA $=$ Juvenile idiopathic arthritis

RA $=$ Rheumatoid arthritis

RF $=$ Rheumatoid factor

\section{REFERENCES}

[1] Deng H, Liu R, Ellmeier W, et al. Identification of a major coreceptor for primary isolates of HIV-1. Nature 1996; 381: 661-6.

[2] Dragic T, Litwin V, Allaway GP, et al. HIV-1 entry into CD4+ cells is mediated by the chemokine receptor CC-CKR-5. Nature 1996; 381: 667-73.

[3] Garred P, Madsen HO, Petersen J, et al. CC chemokine receptor 5 polymorphism in rheumatoid arthritis. J Rheumatol 1998; 25: 1462-5.

[4] Pokorny V, McQueen F, Yeoman S, et al. Evidence for negative association of the chemokine receptor CCR5 $\mathrm{d} 32$ polymorphism with rheumatoid arthritis. Ann Rheum Dis 2005; 64: 487-90.

[5] Prahalad S. Negative association between the chemokine receptor CCR5-Delta32 polymorphism and rheumatoid arthritis: a metaanalysis. Genes Immun. 2006; 7: 264-8.

[6] Prahalad S, Bohnsack JF, Jorde LB, et al. Association of two functional polymorphisms in the CCR5 gene with juvenile rheumatoid arthritis. Genes Immun 2006; 7: 468-75.

[7] Rossol M, Pierer M, Arnold S, et al. Negative association of the chemokine receptor CCR5 d32 polymorphism with systemic 
inflammatory response, extra-articular symptoms and joint erosion in rheumatoid arthritis. Arthritis Res Ther 2009; 11:R91.

[8] van Kuijk AW, Vergunst CE, Gerlag DM, et al. CCR5 blockade in rheumatoid arthritis: a randomised, double-blind, placebocontrolled clinical trial. Ann Rheum Dis 2010; 69: 2013-6.

[9] Lindner E, Nordang GB, Melum E, et al. Lack of association between the chemokine receptor 5 polymorphism CCR5delta32 in rheumatoid arthritis and juvenile idiopathic arthritis. BMC Med Genet 2007; 8: 33

[10] Hinks A, Martin P, Flynn E, et al. Association of the CCR5 gene with juvenile idiopathic arthritis. Genes Immun 2010; 11: 584-9.

[11] Scheibel I, Veit T, Neves AG, et al. Differential CCR5Delta32 allelic frequencies in juvenile idiopathic arthritis subtypes: evidence for different regulatory roles of CCR5 in rheumatological diseases. Scand J Rheumatol 2008; 37: 13-7.

[12] Vargas AE, Marrero AR, Salzano FM, et al. Frequency of CCR5delta32 in Brazilian populations. Braz J Med Biol Res 2006; 39: 321-5.

[13] Grimaldi R, Shindo N, Acosta AX, et al. Prevalence of the CCR5Delta32 mutation in Brazilian populations and cell susceptibility to HIV-1 infection. Hum Genet 2002; 111: 102-4.

[14] Munerato P, Azevedo ML, Sucupira MC, et al. Frequency of polymorphisms of genes coding for HIV-1 co-receptors CCR5 and CCR2 in a Brazilian population. Braz J Infect Dis 2003; 7: 236-40.

[15] Passos Jr GA, Picanco VP. Frequency of the delta ccr5 deletion allele in the urban Brazilian population. Immunol Lett 1998; 61: 205-7.

[16] Pereira RW, Pires RE, Duarte APM, et al. Frequency of the CCR5D32 allele in Brazilians: a study in colorectal cancer and in HTLV-I infection. Genet Mol Biol 2000; 23: 523-6.

[17] Santos NP, Ribeiro-Rodrigues EM, Ribeiro-Dos-Santos AK, et al. Assessing individual interethnic admixture and population substructure using a 48-insertion-deletion (INSEL) ancestryinformative marker (AIM) panel. Hum Mutat 2010; 31: 184-90.
[18] Wedderburn LR, Robinson N, Patel A, Varsani H, Woo P Selective recruitment of polarized Tcells expressing CCR5 and CXCR3 to the inflamed joints of children with juvenile idiopathic arthritis. Arthritis Rheum 2000; 43: 765-74.

[19] Thompson SD, Luyrink LK, Graham TB, et al. Chemokine receptor CCR4 on CD4+ $\mathrm{T}$ cells in juvenile rheumatoid arthritis synovial fluid defines a subset of cells with increased IL-4:IFNgamma mRNA ratios. J Immunol 2001; 166: 6899-906.

[20] Vargas AE, Cechim G, Correa JF, et al. Pros and cons of a missing chemokine receptor--comments on "Is the European spatial distribution of the HIV-1-resistant CCR5-D32 allele formed by a breakdown of the pathocenosis due to the historical Roman expansion?" by Eric Faure and Manuela Royer-Carenzi (2008). Infect Genet Evol 2009; 9: 387-9.

[21] de Kleer IM, Wedderburn LR, Taams LS, et al. CD4+CD25 bright regulatory $\mathrm{T}$ cells actively regulate inflammation in the joints of patients with the remitting form of juvenile idiopathic arthritis. $\mathrm{J}$ Immunol 2004; 172: 6435-43.

[22] Ruprecht CR, Gattorno M, Ferlito F, et al. Coexpression of CD25 and $\mathrm{CD} 27$ identifies FoxP3+ regulatory $\mathrm{T}$ cells in inflamed synovia. J Exp Med 2005; 201: 1793-803.

[23] Chiesa S, Prigione I, Morandi F, et al. Cytokine flexibility of early and differentiated memory $\mathrm{T}$ helper cells in juvenile idiopathic arthritis. J Rheumatol 2004; 31: 2048-54.

[24] Gattorno M, Prigione I, Morandi F, et al. Phenotypic and functional characterisation of $\mathrm{CCR} 7+$ and CCR72 CD4+ memory $\mathrm{T}$ cells homing to the joints in juvenile idiopathic arthritis. Arthritis Res Ther 2004; 7: R256-67.

[25] Dawson TC, Beck MA, Kuziel WA, Henderson F, Maeda N. Contrasting effects of CCR5 and CCR2 deficiency in the pulmonary inflammatory response to influenza A virus. Am J Pathol 2000; 156: 1951-9.

(C) Veit et al.; Licensee Bentham Open.

This is an open access article licensed under the terms of the Creative Commons Attribution Non-Commercial License (http://creativecommons.org/licenses/by-nc/ $3.0 /$ ) which permits unrestricted, non-commercial use, distribution and reproduction in any medium, provided the work is properly cited. 